\title{
Evaluation of Relative Accuracy of Three Commercially Available Removable Die Systems of Different Configurations: An in vitro Study
}

\author{
${ }^{1}$ Shilpi G Gupta, ${ }^{2}$ Rajendra B Hallikerimath, ${ }^{3}$ Nirmala Pasam, ${ }^{4}$ Aman Arora, ${ }^{5}$ Puneet Gupta
}

\begin{abstract}
Introduction: The positional shift observed in removable die systems before and after sectioning the master cast may result in a cast restoration with improper occlusal and proximal contacts and marginal fit, thereby requiring time-consuming chairside adjustments.
\end{abstract}

Aim: This study was done to evaluate the relative accuracy of three commercially available removable die systems with different configurations by measuring the average die displacement before and after sectioning of the cast.

Materials and methods: A total of 60 impressions were made of the standardized brass master model using polyvinylsiloxane. Impressions were divided into three groups. For each group, a different removable die system was used. Group I: cross pin; group II: M R pin; and group III: conventional brass dowel pin. The presectioning measurement both in the horizontal and vertical directions of all the 60 casts obtained were made using profile projector. The casts were then sectioned and removed and replaced 30 times, and the postsectioning measurements were made using the same references. The differences between the presectioning and the postsectioning measurements were calculated Statistical analysis used: The data were analyzed using analysis of variance (ANOVA) and Tukey's multiple comparison test.

Results: All the three die systems exhibited displacement both in the horizontal and vertical directions before and after sectioning the casts. Brass dowel pin exhibited the greatest amount of displacement both in the horizontal and vertical directions.

\footnotetext{
${ }^{1}$ Associate Professor, ${ }^{2}$ Professor and Head, ${ }^{3-5}$ Reader

${ }^{1}$ Department of Prosthodontics, Index Institute of Dental Sciences, Indore, Madhya Pradesh, India

2Department of Prosthodontics, Maratha Mandal's Nathajirao G. Halgekar Institute of Dental Sciences \& Research Centre Belgaum, Karnataka, India

${ }^{3}$ Department of Prosthodontics, Anil Neerukonda Institute of Dental Sciences, Visakhapatnam, Andhra Pradesh, India

${ }^{4}$ Department of Prosthodontics, Sri Guru Ram Das Institute of Dental Sciences \& Research, Amritsar, Punjab, India

${ }^{5}$ Department of Community Dentistry, Government College of Dentistry, Indore, Madhya Pradesh, India

Corresponding Author: Shilpi G Gupta, Associate Professor Department of Prosthodontics, Index Institute of Dental Sciences Indore, Madhya Pradesh, India, Phone: +918827866855, e-mail: shilpigilra@gmail.com
}

Conclusion: The use of more than one pin and the presence of metallic or plastic sleeves can result in improved accuracy and stability of the die system.

Keywords: Conventional brass dowel pin, Cross pin, Dental die, Displacement, Fixed partial denture, M R pin.

How to cite this article: Gupta SG, Hallikerimath RB, Pasam N, Arora A, Gupta P. Evaluation of Relative Accuracy of Three Commercially Available Removable Die Systems of Different Configurations: An in vitro Study. J Oral Health Comm Dent 2017;11(3):68-74.

\section{Source of support: Nil \\ Conflict of interest: None}

\section{INTRODUCTION}

Removable dies for working casts are valuable assets during the laboratory phase of fixed partial denture fabrication. ${ }^{1}$ They facilitate the removal of die for waxing procedure to achieve optimum marginal and proximal contours.

However, separation of individual dies from the working cast requires that the dies should seat in the cast accurately, solidly, and positively in precisely the same position that they had occupied prior to the removal, even after repeated removal during the course of laboratory procedures. ${ }^{1,2}$

This is important in order to maintain an accurate relationship between the prepared teeth, adjacent, and opposing teeth to obtain a cast restoration that has correct occlusal and proximal contours as well as marginal fit. ${ }^{3}$

Over a period of time, various concepts and techniques have been advocated for making removable die systems. ${ }^{4}$

Positional shift in the horizontal and vertical directions has been observed in most of the existing systems. ${ }^{4}$

The present investigation was, therefore, undertaken to determine the relative accuracy of three commercially available removable die systems of different configurations by measuring the average die displacement in the horizontal direction and the vertical direction before and after sectioning of the casts. This can assist dental personnel in selecting a more appropriate removable die system, which would minimize the error and, thereby, contribute to the success of fixed prosthesis. 


\section{MATERIALS AND METHODS}

Astandardized brass master model of specific dimensions was prepared for the study (Fig. 1). The master model simulated a quadrant cast with three evenly spaced machined cylindrical inserts. ${ }^{2}$ The central cylindrical insert was the replica of a preparation to receive a single full metal crown with a uniform shoulder of $1 \mathrm{~mm}$ and a taper of $6^{\circ} .5,6$ The central insert was to be made a removable die.

Two semicircular orientation slots with vertical stops were made at either end of the master model to ensure the repeatability of tray positioning and uniform thickness of the impression material.

Sixty identical rigid custom trays were made using autopolymerizing acrylic resin (DPI-RR, Dental Products of India, Mumbai, India). To provide uniform space for the impression material, first a 3-mm thick sheet of modelling wax (Hindustan Dental Products, Hyderabad, India) was adapted to the master model. ${ }^{1}$ Then, polyvinylsiloxane impression was made of the spaced master model and a cast was made using type III dental stone (Gold stone, Asian chemicals, Rajkot, Gujarat, India).

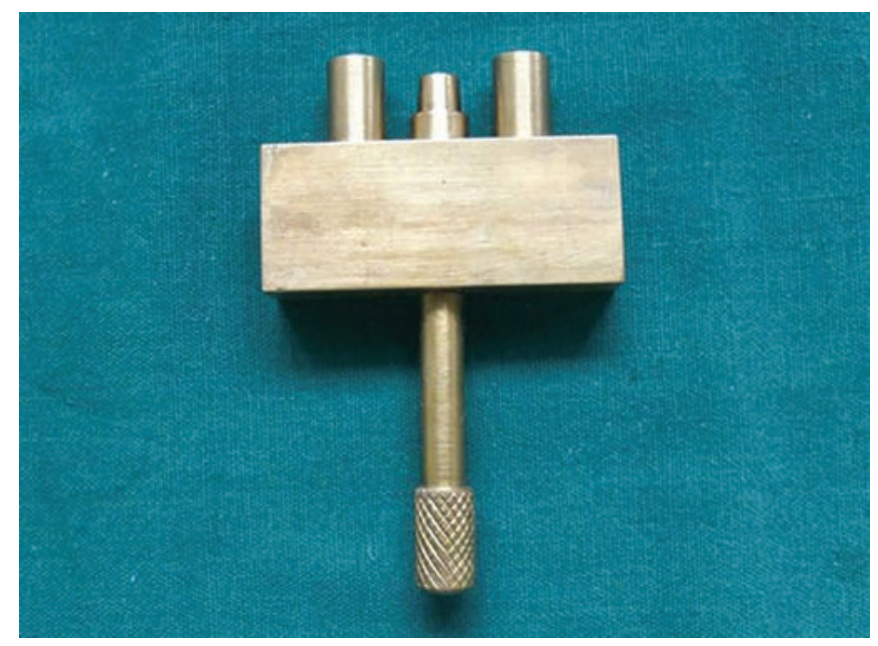

Fig. 1: Standard brass master model

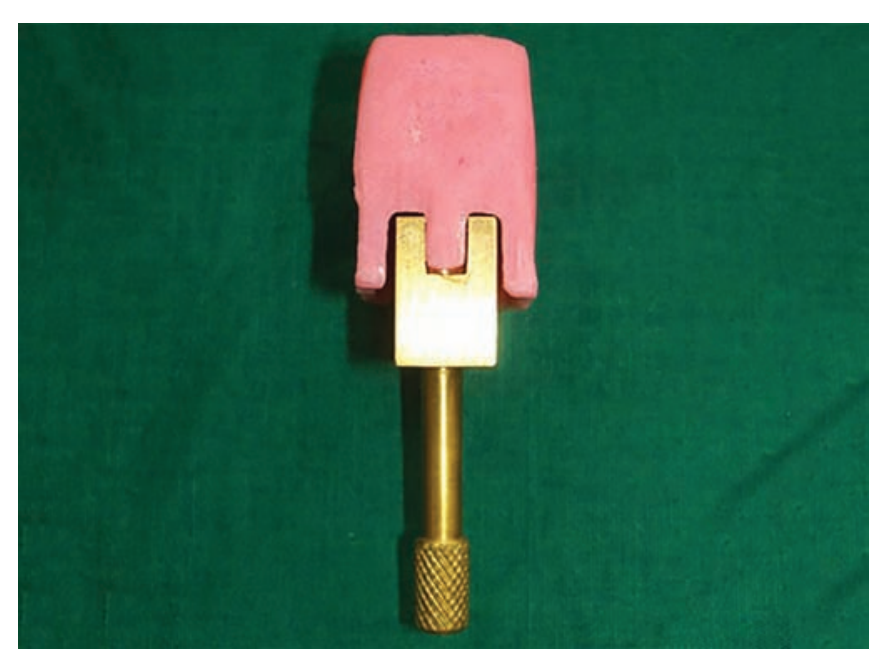

Fig. 2: Impression tray
Over the stone cast, a 2-mm sheet of modelling wax was adapted. The stone cast with the modeling wax was flasked and dewaxed. After wax elimination, the mold space obtained was used to pack dough of autopolymerizing resin to obtain custom trays with identical dimensions.

All the trays were constructed 24 hours prior to making of the impression so as to ensure complete evaporation of the residual monomer and allow the material to become relatively stable. ${ }^{7,8}$

Care was taken not to place any wax in the orientation slots so as to achieve acrylic extensions that are precisely seated into the orientation slots, thus orienting the tray during impression making (Fig. 2).

Before making the impressions, the internal surface of the trays were painted with polyvinylsiloxane tray adhesive (Caulk tray adhesive, Denstply India) and allowed to dry for 15 minutes. ${ }^{5}$

The impression was made using polyvinylsiloxane heavy viscosity (Reprosil-type I very high viscosity, heavy body, Dentsply, Delhi) and light viscosity (Reprosiltype I low viscosity, light body, Dentsply, Delhi). The double-mix single-impression technique was used. ${ }^{7}$

The light body material was loaded into a syringe and inserted around the circular inserts. The heavy body impression material was loaded into the tray, which was positioned on the master model.

The impression tray was placed such that the acrylic extensions were seated directly against the orientation slots to ensure the repeatability of tray positioning and uniform thickness of the impression material. Set impression was removed after 12 minutes $^{6}$ (Fig. 3).

A total of 60 impressions were made, which were divided into three groups each with a different removable die system:

- Group I: Cross pin with plastic sleeve, Harald Nordin SA, Switzerland

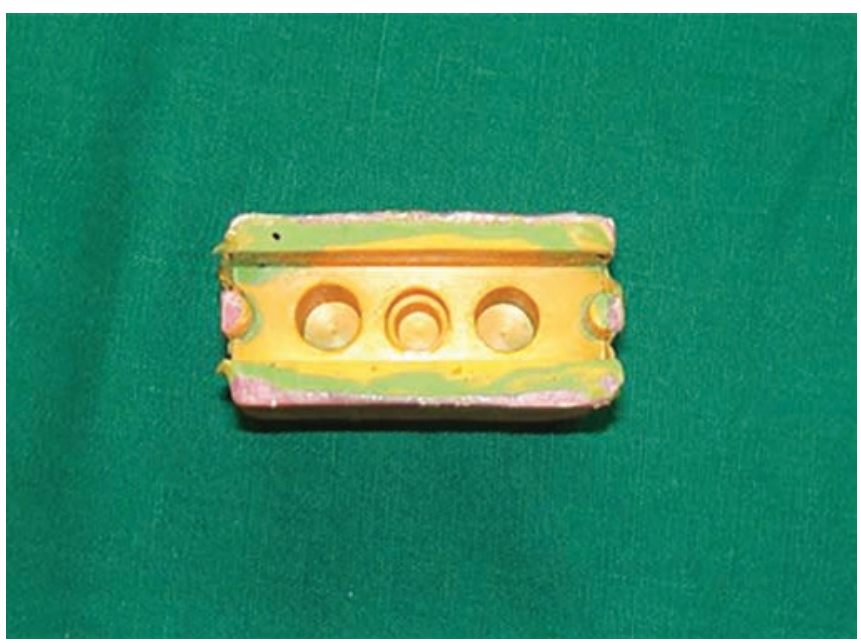

Fig. 3: Impression obtained 
- Group II: M R pin-dual dowel pin with metallic sleeve, Renfert Co, USA

- Group III: Conventional brass dowel pin

For group I, cast were poured in type IV dental stone (Kalrock, Kalabhai Karson Pvt Ltd, Mumbai). The casts were removed from the impression after 1 hour. ${ }^{9}$ After that the base of the cast was trimmed flat on the model trimmer keeping the height as $15 \mathrm{~mm} .{ }^{10}$ To standardize the trimming of all casts, measurement points were placed on both the sides of the cast at $15 \mathrm{~mm}$. The points were joined together by a line on both the sides. The casts were then trimmed using this line as reference (Fig. 4). The trimmed casts were then measured with a digital Vernier caliper to ensure a height of $15 \mathrm{~mm}$.

In this group, the pin was attached to the underside of the cast obtained (postpour technique). ${ }^{9}$ The Pindex system was used to drill holes on the cast to facilitate accurate positioning of the pins. One hole was made at location of the proposed removable die. Two more holes were drilled in the terminal ends of the cast, to

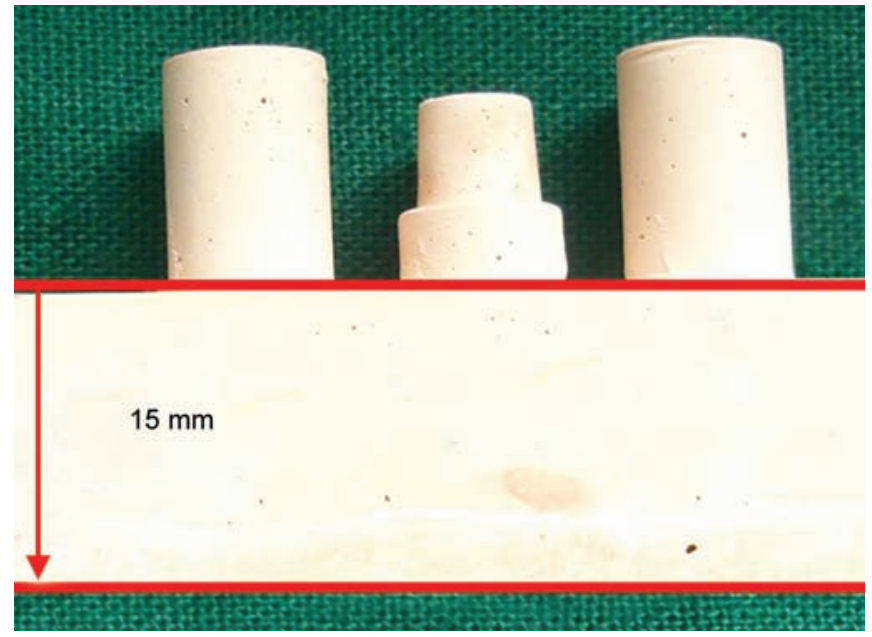

Fig. 4: Cast showing reference lines trimmed to $15 \mathrm{~mm}$

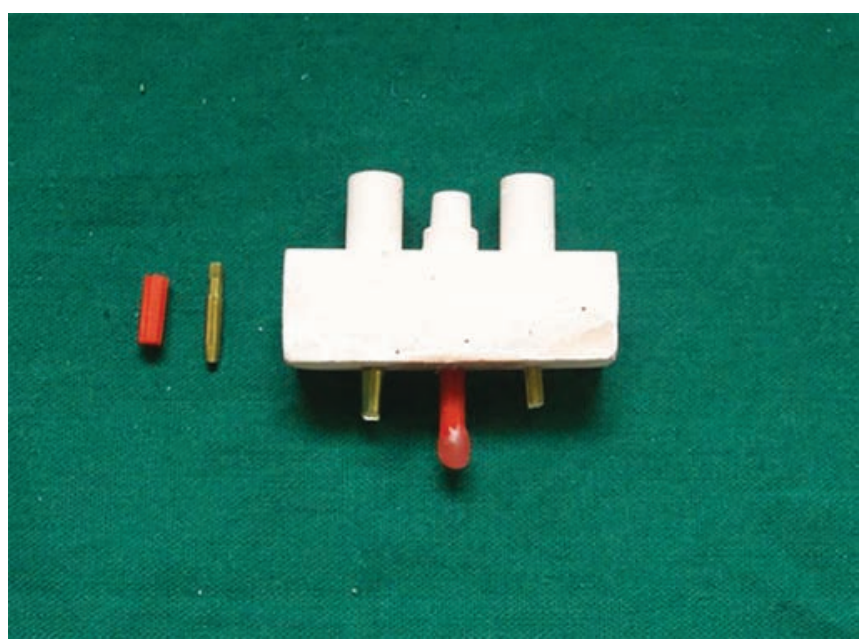

Fig. 5: Pin placement for group I place pins to prevent their separation from the base after sectioning. The cross pin was then secured in the hole corresponding to the proposed removal die with cyanoacrylate cement. Then, the plastic sleeve was inserted onto the cemented pin. Also, the brass dowel pins were placed in the holes corresponding to the terminal ends (Fig. 5).

A small ball of wax was placed on the tip of the dowel pin to locate the pin easily. Separating medium was applied on the area adjacent to dowel pin. A base was poured using type III dental stone (Gold stone, Asian chemicals, Rajkot, Gujarat, India). Once set, the base was trimmed until the wax was exposed. In total, 20 such master casts with bases were obtained.

The cast was poured in a manner similar to group I. The M R pin was secured in the hole corresponding to the proposed removal die with cyanoacrylate cement. Then, the metal sleeve and rubber cap were fitted onto the cemented pin (Fig. 6). A base was poured in a manner similar to group I. Once set, the base was trimmed until the rubber cap was exposed. In total, 20 such master casts with bases were obtained.

In this group, the conventional brass dowel pin was first positioned in the impression and then the cast was poured (prepour technique). ${ }^{9}$ For this, a positioning device made from orthodontic wire was used. ${ }^{11}$

The positioning device along with the dowel pin was positioned in the impression and luted onto the impression using sticky wax (Fig. 7). Impression was poured using type IV dental stone.

Once the stone had set, the positioning device was removed. Two antirotational depressions were made buccally and lingually to the dowel pin with a no. 6 bur to provide additional stability to the die. ${ }^{12}$ Base was poured as for groups I and II. In total, 20 such master casts with bases were obtained.

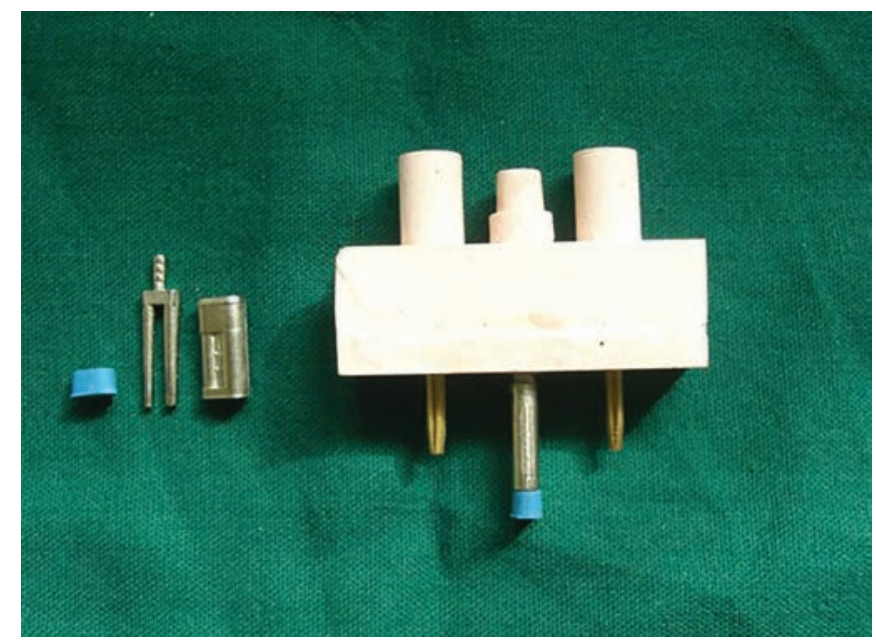

Fig. 6: Pin placement for group II 


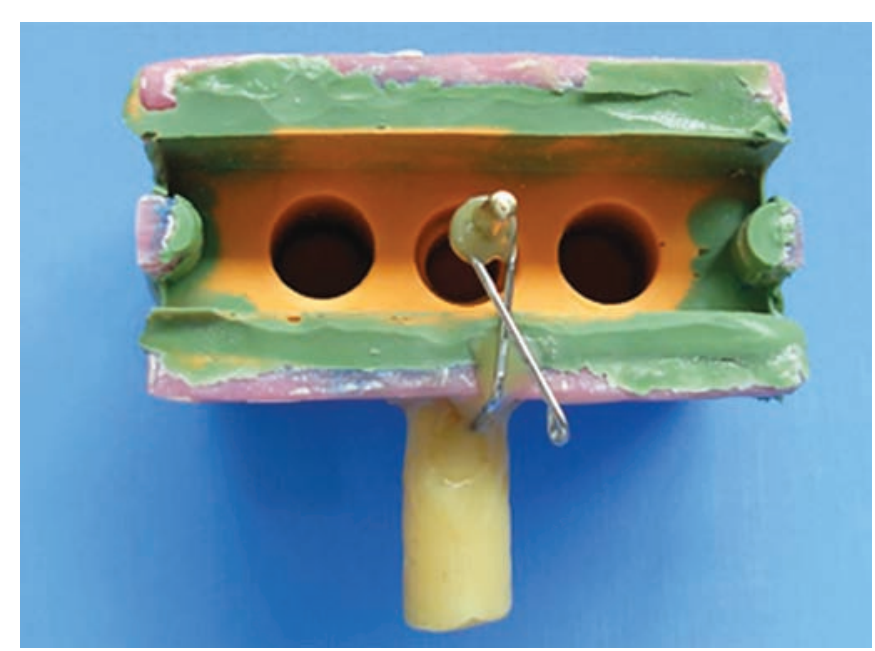

Fig. 7: Pin placement for group III

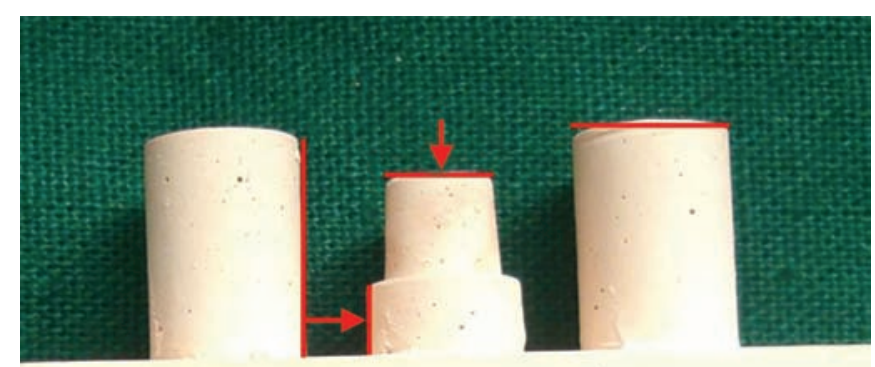

Fig. 9: Schematic diagram showing horizontal and vertical references for measurements

The presectioning measurement of all the 60 casts of three groups was made using profile projector (Model V-12, No 123222, magnification $\times 10$, Nikon, Nippon Kogaku and Japan). The profile projector consists of a screen with horizontal and vertical reference lines and a movable table that allows the object being studied to be positioned on the screen. The device has a light source that projects a magnified image of the object onto the screen in the form of a shadow, so that the sharp edges of silhouette become the reference lines of measurement ${ }^{1}$ (Fig. 8).

Measurements up to the resolution of $0.001 \mathrm{~mm}$ are automatically recorded on a quadracheck 2000, which is connected to the profile projector. For measurement, the cast was secured to the holding device of the profile projector. Both horizontal and vertical measurements were made between the reference lines as shown in Figure 9. Measurement in horizontal direction was in a mesiodistal direction. Each individual measurement was made three times and the mean of the three measurements was taken as the final measurement to reduce variation. ${ }^{1}$

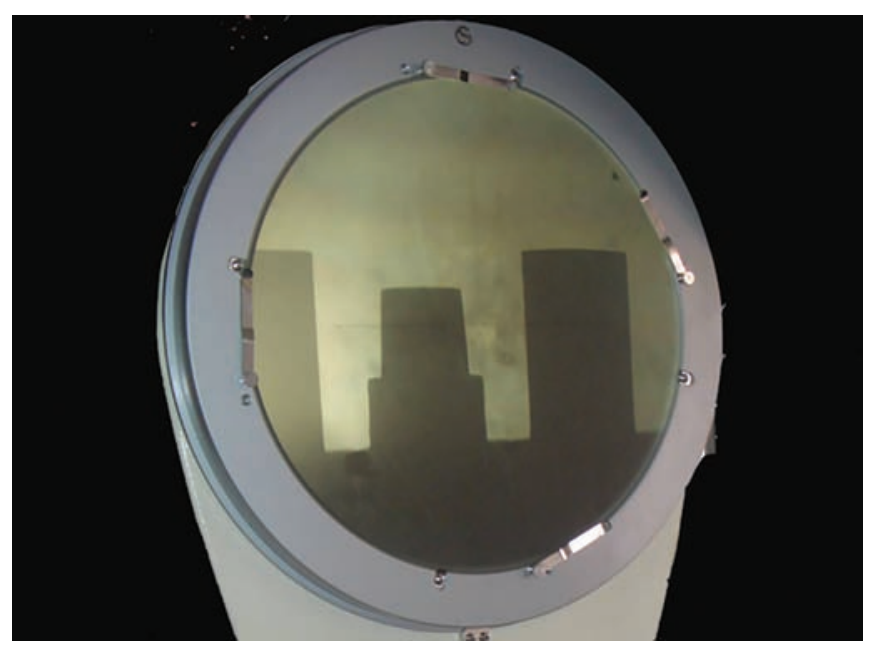

Fig. 8: Presectioned cast focused for measurement

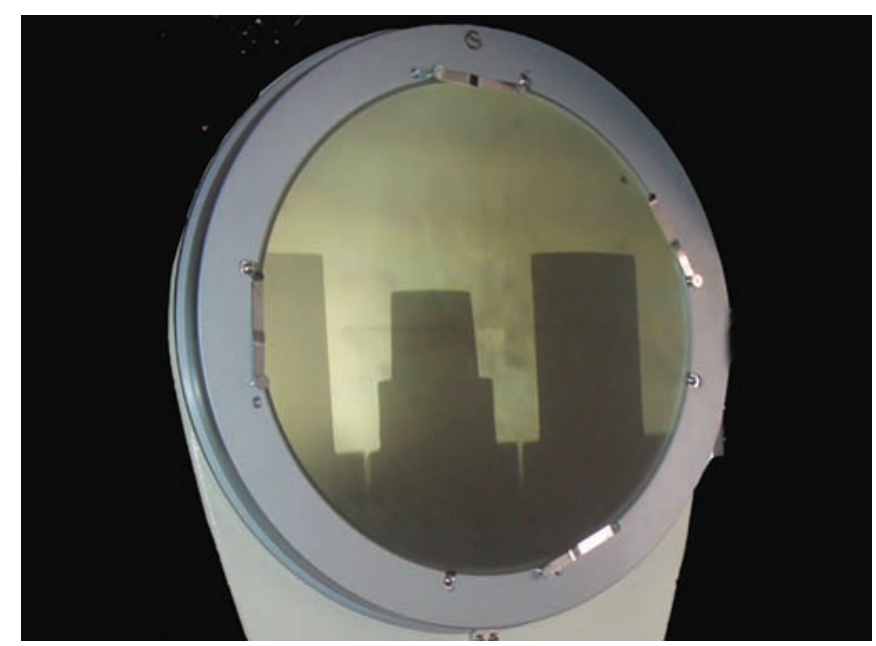

Fig. 10: Postsectioned cast focused for measurement

The central cylindrical insert of the master cast, which was prepared to receive a full metal crown, was sectioned to make a removable die. The sectioning was done using a laser-guided die-cutting machine (Diacut Vario, Amann Girrbach, Germany). Each die was removed and replaced 30 times on its base simulating the average amount of handling during the laboratory procedures. All the dies and cast were cleaned and repositioned prior to final measurements. $^{12}$

The postsectioning measurements were recorded in a manner similar to the presectioning measurements using the same reference lines (Fig. 10). The difference between the presectioned and the postsectioned measurements was determined and recorded. This indicated the amount of horizontal and vertical shifts of the die within each group.

\section{RESULTS}

Multiple comparisons between the means were analyzed by Tukey's test. All significance levels below the 5\% level were accepted as statistically significant $(\mathrm{p}<0.05)$. 
Table 1: Horizontal displacements

\begin{tabular}{lllll}
\hline & & Group I & Group II & Group III \\
\hline Presectioning values & Mean & 3.2120 & 3.2124 & 3.2130 \\
& SD & 0.0035 & 0.0025 & 0.0023 \\
Postsectioning values & Mean & 3.2196 & 3.2290 & 3.1382 \\
& SD & 0.0252 & 0.0160 & 0.0729 \\
Absolute displacement & Mean & 0.0208 & 0.0192 & 0.0871 \\
& SD & 0.0155 & 0.0135 & 0.0565 \\
\hline
\end{tabular}

SD: Standard deviation

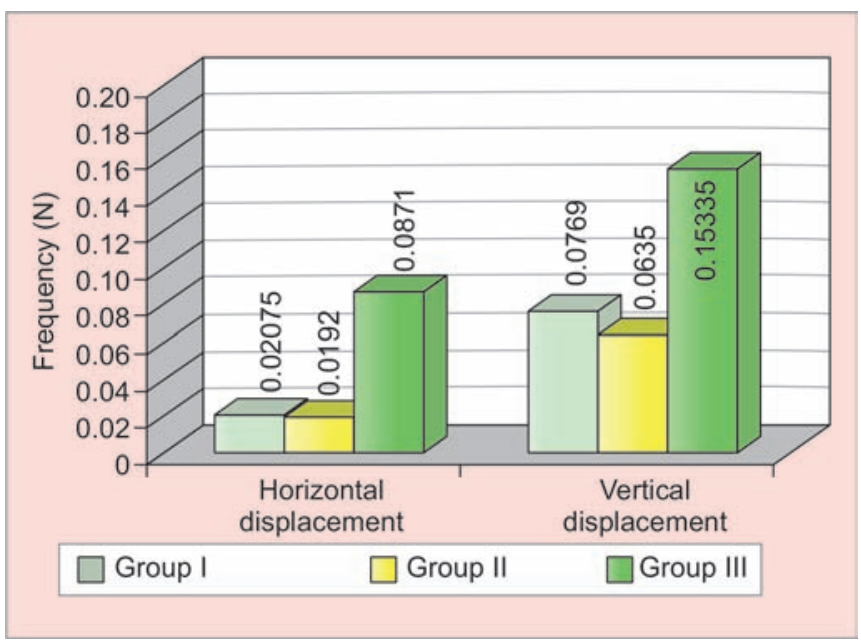

Graph 1: Mean horizontal and vertical displacements

All the dies in the three groups exhibited difference between the presectioning and the postsectioning measurements. This difference indicated the amount of vertical and horizontal displacements of each die within a group.

Tables 1 and 2 show the mean die displacement both in the horizontal and the vertical directions for each group respectively. Group III showed maximum mean displacement both in horizontal and vertical directions as shown in Graph 1.

The data were analyzed using one-way ANOVA. All significance levels below the $5 \%$ level were accepted as statistically significant $(\mathrm{p}<0.05)$. The ANOVA demonstrated statistically significant difference between the three groups for both the mean horizontal and the mean vertical displacements.

Tukey's test was used to analyze the difference in mean displacement between the three groups. There
Table 2: Vertical displacements

\begin{tabular}{lllll}
\hline & & Group I & Group II & Group III \\
\hline Presectioning values & Mean & 2.4896 & 2.4868 & 2.4866 \\
& SD & 0.0084 & 0.0071 & 0.0050 \\
Postsectioning values & Mean & 2.4122 & 2.4241 & 2.3333 \\
& SD & 0.0384 & 0.0380 & 0.0286 \\
Absolute displacement & Mean & 0.0769 & 0.0635 & 0.1534 \\
& SD & 0.0429 & 0.0363 & 0.0287 \\
\hline
\end{tabular}

SD: Standard deviation

was a significant difference in the displacement between group III when compared with both groups I and II in both horizontal and vertical directions. No significant difference was observed between groups I and II in both horizontal and vertical directions as shown in Tables 3 and 4 respectively.

\section{DISCUSSION}

In the present study, all the dies in the three groups exhibited difference between the presectioning and the postsectioning measurements. This was in agreement with the result of the other investigators. ${ }^{2,3,12-17}$ This difference indicated the amount of vertical and horizontal displacements of each die within a group.

The displacement exhibited both a positive value and a negative value. A positive value in vertical displacement indicated elevation of the die, i.e., incomplete seating of the die in the cast and the negative value indicated depression of the die. A positive value in the horizontal displacement indicated that the distance between the dies has decreased, and the negative value indicated that the distance between the dies has increased.

It was seen that the horizontal shift of the dies was inconsistent. In some, the distance between the dies decreased and, in some, it increased. However, the vertical shift of the die was nearly always in the positive direction, i.e., elevation of the die. This was similar to the results obtained in the previous studies. ${ }^{2,3,12,14}$

The displacement of the dies can be attributed to:

- The frictional wearing of the keyways during repeated removal and repositioning,

- Particles of debris trapped in the keyway,

- Release of internal stresses in the stone once the cast is sectioned.
Table 3: Tukey's test for horizontal displacements

\begin{tabular}{llll}
\hline Groups & Group I & Group II & Group III \\
\hline I & & $p=0.989$ not & $p<0.05$ \\
& & significant & significant \\
II & $p=0.989$ not & & $p<0.05$ \\
& significant & & significant \\
III & $p<0.05$ significant & $p<0.05$ significant & \\
\hline
\end{tabular}

Table 4: Tukey's test for vertical displacements

\begin{tabular}{llll}
\hline Groups & Group I & Group II & Group III \\
\hline I & & $p=0.480$ not & $p<0.05$ \\
& & significant & significant \\
II & $p=0.480$ not & & $p<0.05$ \\
& significant & & significant \\
III & $p<0.05$ significant & $p<0.05$ significant & \\
\hline
\end{tabular}


- Inherent expansion of stone and the additional expansion of the second pour of stone used to provide a base.

In the present study, it was found that group III showed maximum mean displacement both in horizontal and vertical directions, which was statistically significant. However, no significant difference was observed between groups I and II in both horizontal and vertical directions.

The results obtained in the present study can be attributed to the difference in the configuration of the three removable die systems used. The MR pin (group II) exhibited the least amount of displacement both in the horizontal and vertical directions. This could be due the presence of dual pins in this system (the other systems had one pin), which minimized the rotation of the die.

The dual pins were housed in a metallic sleeve, which secured the die firmly into position even after repeated removal and insertion. The sleeve also prevented the pin from abrading the stone base resulting in greater accuracy. ${ }^{12,15}$ Also, the rubber cap helped to provide pin relief to facilitate easy removal of the pin, thus preventing burring of the dowel pin and subsequent damage to the dowel channel, which occurred due to forceful removal of pin. Also the use of postpour technique, i.e., Pindex system, may have improved the accuracy as it eliminated guesswork and facilitated the precise positioning of the pins.

The accuracy of cross pin (group I) was found to be less than M R pin (group II) although the difference was not significant. This could be due to the presence of a single pin. Also, this can be attributed to the presence of a plastic sleeve. The expansion of the stone creates stress at the stone-plastic interface, which results in pressure, which may prevent the pins from fully seating after repeated removal and insertion. ${ }^{15}$

The conventional dowel pin (group III) exhibited the greatest displacement both in the horizontal and the vertical directions and the difference was statistically significant when compared with groups I and II. This can be attributed to the presence of single pin, which failed to provide as much antirotational resistance as the double pin.

Moreover, the absence of the sleeve resulted in a direct stone-pin interface, which leads to frictional wear of the keyways during repeated removal and insertion leading to greater inaccuracies. The prepour technique may also have contributed to the inaccuracy, as in this technique, it was difficult to precisely position the pins and maintain them in that position while the stone set.

\section{CONCLUSION}

Based on the results of the present study, the following conclusions can be drawn:

- All the three die systems exhibited displacement both in the horizontal and vertical directions before and after sectioning the casts.

- Conventional brass dowel pin exhibited significantly greater amount of die displacement both in the horizontal and the vertical directions among all the three systems.

- The M R pin exhibited the least amount of displacement both in the vertical and horizontal directions among all the three systems. While significant difference was found in the mean horizontal and vertical die displacements between M R pin and the conventional brass dowel pin, the difference was not significant between M R pin and cross pin.

- The use of more than one pin (double pins) and the presence of metallic or plastic sleeves can significantly improve the accuracy and stability of the die system, thereby, reducing chairside adjustments.

\section{REFERENCES}

1. Aramouni P, Millstein P. A comparison of the accuracy of two removable die systems with intact working casts. Int J Prosthodont 1993 Nov-Dec;6(6):533-539.

2. Myers M, Hembree JH Jr. Relative accuracy of four removable die systems. J Prosthet Dent 1982 Aug;48(2):163-165.

3. Dilts WE, Podshadley AG, Sawyer HF, Neiman R. Accuracy of four removable die techniques. J Am Dent Assoc 1971 Nov;83(5):1081-1085.

4. Richardson DW, Sanchez RA, Baker PS, Haug SP. Positional accuracy of four die tray systems. J Prosthet Dent 1991 Jul;66(1):39-45.

5. Millstein P, Maya A, Segura C. Determining the accuracy of stock and custom tray impression/casts. J Oral Rehabil 1998 Aug;25(8):645-648.

6. Johnson GH, Craig RG. Accuracy of four types of rubber impression materials compared with time of pour and a repeat pour of models. J Prosthet Dent 1985 Apr;53(4):484-490.

7. Thongthammachat S, Moore BK, Barco MT 2nd, Hovijitra S, Brown DT, Andres CJ. Dimensional accuracy of dental casts: influence of tray material, impression material, and time. J Prosthodont 2002 Jun;11(2):98-108.

8. Stewardson DA. Trends in indirect dentistry: 5. Impression materials and techniques. Dent Update 2005 Sep;32(7):374-376, 379-380, 382-384.

9. Shillinburg, HT Jr.; Hobo, S.; Whitsett, LD., et al. Fundamentals of fixed prosthodontics. 3rd ed. Chicago: Quintessence Publishing Co Inc; 1997.

10. Malonw, WFP.; Koth, DL. Tylman's theory and practice of fixed prosthodontics. St Louis (MO): Ishiyaku Euroamerica Inc; 1989.

11. George TA, Holmes JR. The dowelklip: a device for dowel pin placement. J Prosthet Dent 1985 Feb;53(2):276-278.

12. Covo LM, Ziebert GJ, Balthazar Y, Christensen LV. Accuracy and comparative stability of three removable die systems. J Prosthet Dent 1988 Mar;59(3):314-318. 
13. Rhoads, JE.; Rudd, KD.; Morrow, RM. Dental laboratory procedures fixed partial dentures. Vol. 2. St. Louis (MO): The CV Mosby Company; 1986.

14. Miranda FJ, Dilts WE, Duncanson MG Jr, Collard EW. Comparative stability of two removable die systems. J Prosthet Dent 1976 Sep;36(3):326-333.

15. Serrano JG, Lepe X, Townsend JD, Johnson GH, Thielke S. An accuracy evaluation of four removable die systems. J Prosthet Dent 1998 Nov;80(5):575-586.
16. Sivakumar I, Mohan J, Arunachalam KS, Zankari V. A comparison of the accuracy of three removable die systems and two die materials. Eur J Prosthodont Restor Dent. 2013 Sep;21(3):115-119.

17. Ahmad M, Balakrishnan D, Narayan AI. A comparative evaluation of linear dimensional accuracy of the dies obtained using three conceptually different die systems in the fabrication of implant prosthesis: an in vitro study. Indian J Dent Res. 2014 Mar-Apr;25(2):197-203. 